\title{
Interactive comment on "Chemical Characteristics of Marine Fine Aerosols over Sea and at Offshore Islands during Three Cruise Sampling Campaigns in the Taiwan Strait- Sea Salts and Anthropogenic Particles" by Tsung-Chang Li et al.
}

\section{Anonymous Referee \#3}

Received and published: 6 October 2016

Review for "Chemical Characteristics of Marine Fine Aerosols over Sea and at Offshore Islands during Three Cruise Sampling Campaigns in the Taiwan Strait- Sea Salts and Anthropogenic Particles" by Li et al. submitted to ACPD

This paper presents filter-based PM2.5 composition measurements area over Taiwan strait where is not well characterized and compares with the condition at an offshore island site in Penghu island. This is a high quality data set and an important contribution to the field. I do recognize that this is a data set over a large marine area with different cruises and as such it is difficult to analyze, but I do not think the analysis at present is

Printer-friendly version

Discussion paper 
as thorough and coherent as it could be.

Overall comments: This paper presents almost all the compositions can be measured in PM2.5 in three courses over Taiwan strait, including the major ions, heavy metals and OCEC. The data quality is good however the overall impression is the authors just showed so much data there and did not find any impressed or interesting findings. I suggest to submit to other popular journals such as Atmospheric Environment or Atmospheric Research, unless the author can provide any interesting findings after further analysis.

Detailed comments: A The tables and figures A1: Units need to be added to the table 235 A2: Sample numbers should be added in table 1. Actually I was confused about the sampling method. Totally how many valid filters were collected in different cruises? If the filters of PM2.5-10 were contaminated, it can be moved to the supplemented materials as there are no important results. A3: Tables can contain large information than the one can be illustrated in the manuscript. The authors do not need to mention every data in the tables, but need to add some comparisons with the data in other literatures to rich the contents. Some interesting findings can be discovered during this process..

B Logic B1: The major discussion including seven sections, and less comparison with the data over other areas, which makes the reader feel that the author is just loading the data. It is better to find some internal connection between these data and name each section following the findings. Or the author could try 3.1.1 to including some sections into one section. e.g. 3.3, 3.4 and 3.5 are all about the sea salt particles, which can be in one section. B2: The outline really need to be reconstructed. I often have this problem with my paper that the closely related information is not discussed until much later in the paper. Please try to discuss, at least briefly, all the relevant information on a topic at one place. Otherwise, some issues sounds like mentioned several times. Language or content can be more condensed.

Interactive

comment
Printer-friendly version

Discussion paper 
C Detailed comments C1: The weather condition should be also mentioned at first as the sampler number is limited and the reader need some general idea on the background air mass condition. C2: Page 6 line 30 section 3.2: It should be ammoniumpoor area that (NH4)2SO4 is not favored. NH4HSO4 is more likely. C3: Page 8 line 9. the data obtained by equation(1) is in the middle level of these three results, however it is not a reason that "the most accurate method to estimate the sea salt concentrations was equation (1)". C4: Page 9 line 10-15 about the anthropogenic particle influence, it can be one important topic in this manuscript. Suggest the authors make two major concern: anthropogenic source and sea salts $\mathrm{Cl}$ deficit. Besides Section 3.5 title is missing in the manuscript. C5:Page 12 line 30, an accurate (OC/EC)pri value used in this study should be mentioned in the manuscript. The discussion of OCEC is really poor.

Interactive comment on Atmos. Chem. Phys. Discuss., doi:10.5194/acp-2016-384, 2016. 